\title{
From introduction to equilibrium: reconstructing the invasive pathways of the Argentine ant in a Mediterranean region
}

\author{
NÚRIA ROURA-PASCUAL*†, JOSEP M. BAS*, WILFRIED THUILLER ${ }^{*}$ CANG HUI†, \\ RAINER M. KRUG§† and LLUÍS BROTONS \\ *Departament de Ciències Ambientals, Universitat de Girona, Campus de Montilivi, 17071 Girona, Catalonia, $\dagger$ Department of \\ Botany and Zoology, Centre for Invasion Biology, Stellenbosch University, Private Bag X1, Matieland 7600, South Africa, \\ $\ddagger$ Laboratoire d'Ecologie Alpine, UMR-CNRS 5553, Université J. Fourier, BP 53, 38041 Grenoble Cedex 9, France, §Plant \\ Conservation Unit, Department of Botany, University of Cape Town, Private Bag X3, Rondebosch 7701, South Africa, 9 Centre \\ Tecnolgic Forestal de Catalunya, Àrea de Biodiversitat, Pujada del Seminari s/n, 25280 Solsona, Spain
}

\begin{abstract}
Determining the geographical range of invasive species is an important component of formulating effective management strategies. In the absence of detailed distributional data, species distribution models can provide estimates of an invasion range and increase our understanding of the ecological processes acting at various spatial scales. We used two complementary approaches to evaluate the influence of historical and environmental factors in shaping the distribution of the Argentine ant (Linepithema humile), a widespread, highly invasive species native to South America. Occurrence data were combined with environmental data at incremental spatial scales (extent and resolution) to predict the suitable range of the ant invasion using ecological niche models. In addition, we also used a spread model that simulated the jump dispersal of the species to identify the most plausible scenarios of arrival of L. humile in the NE Iberian Peninsula at local scales. Based on the results of both modelling practices, we suggest that L. humile might have reached its maximum geographic range at regional scales in the NE Iberian Peninsula. However, the species does not appear in equilibrium with the environment at small spatial scales, and further expansions are expected along coastal and inland localities of the Costa Brava. Long-distance jumps are ultimately responsible for the spread of the Argentine ant in the area. Overall, our study shows the utility of combining niche based models with spread models to understand the dynamics of species' invasions.
\end{abstract}

Keywords: biological invasion, ecological niche models, geographic distribution, Linepithema humile, NE Iberian Peninsula, pathways of introduction, spatial scales, spread models

Received 17 September 2008; revised version received 19 February 2009 and accepted 23 February 2009

\section{Introduction}

An important consequence of globalization is the increase in biotic exchange among regions worldwide. The movement of species far away from their native ranges produces a gradual replacement of native biota, often exacerbating the threats already posed by changes in biodiversity (Mack et al., 2000). Under these circumstances, the identification of areas at risk of invasion, as

Correspondence: Núria Roura-Pascual, Departament de Ciències Ambientals, Universitat de Girona, Campus de Montilivi, 17071 Girona, Catalonia, tel. +27 218083 974, fax + 27218082 995, e-mail: nrourapascual@gmail.com well as the pathways of introduction and the rate at which species spread are of paramount importance to the control of nonnative species (Hulme, 2003). Determining the spatial dimensions of invasive species is not only valuable for management purposes, it also provides excellent opportunities to test hypotheses about the underlying processes controlling the spread of introduced populations and resolve interesting questions in invasion biology.

As such, modelling practices are acquiring greater importance among researchers interested in assessing the boundaries of biological invasions (Peterson, 2003). Both ecological niche and spread models have been used for such purposes. Ecological niche models corre- 
late environmental variables that influence species' ecology with occurrence/abundance data to identify areas suitable for the species (Guisan \& Thuiller, 2005). On the other hand, spread models simulate the spatiotemporal dynamics of species by not only considering variations in the environment, but also the underlying processes driving range expansion and the characteristics of species (Higgins \& Richardson, 1996). While ecological niche models provide a relatively easy technique to assess the susceptibility of an area to become invaded, models need to consider the spatial dynamics of species to estimate their current distribution and the time required for an area to become invaded (Hulme, 2003). Therefore, the major challenge that spread models face is to integrate the various modes of a species' dispersal (spread by diffusion and long-distance jump dispersal) into a realistic simulation model (Hastings et al., 2005).

Despite their inherent complexities, both ecological niche and spread models have been successfully applied to estimate the geography and dynamics of several invasive species (Higgins et al., 1996; Peterson, 2003). Additionally, recent studies have shown the potential when combining both modelling techniques (Meentemeyer et al., 2008; Pitt et al., 2009). Such integrated approaches permit a more comprehensive interpretation of the species' ecology and spread in heterogeneous landscapes. This is especially important for invasive species, since it allows developing robust assessments about the areas susceptible for future establishment and/or infer hypothesis about the pathways of expansion.

The aim of this study is to provide a better understanding of the geographic limits of a highly invasive species by combining ecological niche and dynamic spread modelling techniques. We provide new insights into the processes that influence the expansion of biological invasions, by using the Argentine ant (Linepithema humile) as a study case. The methodological approach is composed of two major steps, each addressing one of the questions below:

(1) Question 1: Is Argentine ant invasion in equilibrium with its environment? We calibrated a series of ecological niche models at various spatial scales (i.e. different extent and resolution), which allowed us to identify the most influential environmental factors and elucidate the status of the invasion by comparing final predictions.

(2) Question 2: What are the main pathways of introduction and expansion of the Argentine ant? By means of a spread model, we tested several hypotheses about the possible introduction of the species and its subsequent expansion at local scales.
The combination of both approaches enabled us to clarify the role of ecologic and anthropogenic factors in shaping the current distribution of the Argentine ant at the NE Iberian Peninsula at incremental spatial scales (Fig. 1), and identify potential scenarios of introduction by linking this local invasion process to the pathways of species spread at the global scale.

\section{Methods}

\section{Study species}

Native to South America, L. humile is considered as one of the world's worst invasive species (Lowe et al., 2000). Despite their limited dispersal abilities (i.e. absence of winged dispersal by queens, and colonies only grow and bud off into separate units an averaged distance of $150 \mathrm{~m} \mathrm{yr}^{-1}$ ), Argentine ants have been able to establish in many Mediterranean and subtropical areas primarily due to long-distance jump dispersal associated with humans (Suarez et al., 2001). The first observations of the invasion in the Iberian Peninsula date back to 1894 in Oporto (western side) and 1923 (probably 1919) in València (eastern side). L. humile is currently distributed along coastal areas and in some inland localities (Espadaler \& Gómez, 2003). Although the processes responsible for this distribution are unknown, it is possible that Argentine ants may have been introduced directly from its native range via various trans-Atlantic routes that connected South America with the Iberian Peninsula during the last centuries (Barbaza, 1988; Yáñez, 1996). However, the strong relationship between southwestern Iberian Peninsula (Portugal; Extremadura and Andalusia, Spain) and cork industries located at the northeastern side (Barbaza, 1988) could also have been the cause of long-distance dispersal of Argentine ant populations within the Peninsula.

\section{Correlative modelling approach to identify suitable areas across spatial scales}

In ecological niche models, occurrence and environmental data influencing species' distributions are combined into a statistical model to determine the role of environmental factors, and predict those areas suitable for the species. As models are sensitive to calibration data and spatial scales (McPherson et al., 2006; Menke et al., 2009), we estimated the potential distribution of Argentine ants at the NE Iberian Peninsula using independent occurrence datasets at global (worldwide), regional (Catalonia) and local (Costa Brava) scales. Global scale models were calibrated using a wider range of environmental conditions, and were therefore expected to perform better in estimating the potential 
range of the species than those models calibrated using a narrow range. On the other hand, local scale models dealt well with the fine-scale heterogeneity of the landscapes (Thomas \& Abery, 1995; Guisan et al., 2007). Therefore, by comparing them, we expected to test hypotheses about the status of the invasion; the closer
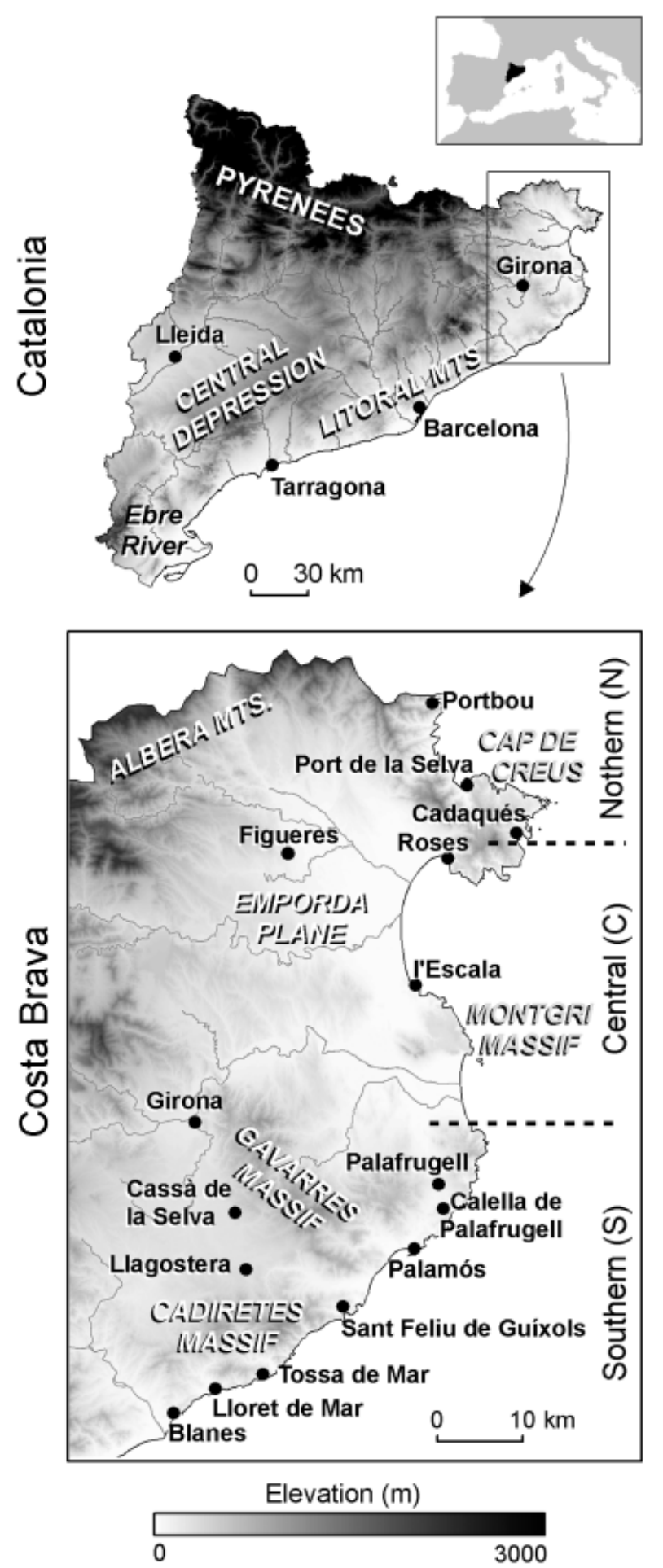

the concordance among predictions, the more likely the species is at equilibrium with its environment (i.e. the species has reached all its suitable areas and no further expansion is expected) at that specific spatial scale. Although a similar conclusion can be drawn by looking at the performance of the models (i.e. the higher the value of the performance index, the closer to equilibrium), indices were not directly comparable because models were calibrated using independent occurrence datasets and evaluated with testing data at different prevalence (Manel et al., 2001; McPherson et al., 2006).

We used generalized additive models (GAM) to assess the potential distribution of the species. GAMs are semiparametric extensions of generalized linear models, which allow for nonparametric and complex relationships between the response and predictor variables in addition to the parametric forms (Hastie \& Tibshirani, 1990). A nonparametric smoothed function of all explanatory variables is fitted to the response variable without prejudging the shape of the relationship between both terms. Consequently, it attains more complex response curves than most classical linear models. We used a cubic spline smoother, and the appropriate level of smoothness for each predictor was bounded to four.

Instead of applying a usual stepwise selection procedure using Akaike's information criterion (AIC, Akaike, 1974) to select the most parsimonious solution among several models, we used a multimodal inference method to estimate the weights of evidence for each variable and predict the distribution of the species (Burnham \& Anderson, 2002). Multimodal inference makes inference based on multiple models and generates a final weighted average prediction, giving higher weight to models with higher relevance. The weight in favour of

Fig. 1 Locality maps for Catalonia and Costa Brava, indicating the main topographic features and the most important urban centres. Darker shades indicate higher altitudes, and linear features main watercourses. Northern $(\mathrm{N})$, central $(\mathrm{C})$ and southern (S) sections of the Costa Brava are differentiated according to the main water basin and main topographic and geologic units. [The $\mathrm{N}$ area is a schistous massif (named Cap de Creus) with Mediterranean shrubland vegetation influenced by strong northern winds. The $\mathrm{C}$ area (encompassing Golf of Roses and Begur Massif) presents an heterogeneous landscape mainly composed of sedimentary, intensively cultivated plains and small calcareous and siliceous massifs (mainly covered by kermes oak forests accompanied by aleppo pines), considerably shaped by human presence. The $S$ area is a low granite mountain range (Gavarres-Cadiretes massif) mainly covered by cork oak forests, highly influenced by nearby urban concentrations. All three areas are affected by fast-growing urbanization processes, which are strong in the South and near the coastline]. 
each model $\left(w_{i}\right)$ is estimated by:

$$
w_{i}=\frac{\exp \left(-\frac{1}{2} \Delta_{i}\right)}{\sum_{r=1}^{R} \exp \left(-\frac{1}{2} \Delta_{r}\right)},
$$

where $\Delta_{i}$ corresponds to the difference between the AIC of the model $(i)$ and the minimum AIC value of all possible combinations of variables. By analogy, the weight of evidence of each predictor variable is estimated as the sum of the model weight over all models in which the selected predictors appear. The calculation of the absolute weight of evidence is then done through a randomization procedure, in which each predictor variable is randomly permutated in the original dataset to assess its absolute influence on the response variables. This approach is appealing because it reduces biases due to model selection and infers the importance of each variable across all the fitted models, and not only based on one single stepwise selected model (Thuiller et al., 2007).

Before the development of the models, occurrence data at each spatial scale were randomly divided into two datasets for calibrating (70\%) and testing (30\%) models, respectively. Model validation was done using the testing data set aside from model development at each spatial scale and the area under the receiver operating characteristic (ROC) curve (AUC), where values of 0.5 indicate model discrimination no better than random and values of 1 highest model agreement (Hanley \& McNeil, 1982). Since ROC analysis could have been affected by differences in the range of predictions (Lobo et al., 2008), a series of additional parameters were also reported: $\kappa$ index at the threshold that maximizes the parameter, and specificity and sensitivity (i.e. proportion of correctly predicted presences and absences, respectively) measured at the threshold that maximizes the sum of both parameters (i.e. also known as the Youden's index, this criteria minimizes the mean error rate for positive observations and the error rate for negative observations) (Youden, 1950). All analyses were conducted in R v2.5.1 ( $\mathrm{C}$ R Foundation for Statistical Computing, Vienna, Austria), and model performance parameters were calculated using the PresenceAbsence Model Evaluation package (Freeman, 2007).

Occurrence data. Occurrence data from native (64 presences) and worldwide invaded (650 presences) ranges were extracted from Roura-Pascual et al. (2004) to calibrate and evaluate the model at global scales at the aforementioned proportions. Since absence data were not available, an equal number of pseudoabsences were randomly generated around areas densely sampled from the overall study area without confirmed presence of the species. In contrast, the regional dataset was composed of 125 presences and 77 absences extracted from personal collections and an urban survey, during which the main human settlements in Catalonia were surveyed for Argentine ants (half an hour searching at each) during summer 2003 (Fig. 2). The local dataset consisted of 1120 absences and 817 presences obtained strictly from a road survey carried out during summers 2004 and 2005. The main roads of the Costa Brava were surveyed at intervals of 500-1000 m distance; at these stopping sites, we searched for Argentine ants within a radius of $10 \mathrm{~m}$ for a time period of $10 \mathrm{~min}$ (Fig. 2).

Environmental datasets. For the model at global scales, we used six climatic variables: annual precipitation $\left(P_{\mathrm{AN}}\right)$, mean diurnal range, minimum temperature of the coldest month (TMIN), maximum temperature of the warmest month (TMAX), precipitation of the coldest quarter $\left(P_{\mathrm{CQ}}\right)$, and precipitation of the warmest quarter $\left(P_{\mathrm{WQ}}\right)$ from the WorldClim (Hijmans et al., 2005; $1 \mathrm{~km} \times 1 \mathrm{~km})$. For the regional and local models, we used eight digital coverages summarizing aspects of topography [aspect (ASP), slope (SLO), and topographic position index (TPI), derived from the Digital Elevation Model of Catalonia (ICC, 2008; $30 \mathrm{~m} \times 30 \mathrm{~m})$ ], climate [annual solar radiation $\left(R_{\mathrm{AN}}\right)$, annual mean precipitation $\left(P_{\mathrm{AN}}\right)$, mean winter minimum temperatures $\left(T_{\text {WI }}\right)$, and mean summer maximum temperatures $\left(T_{\mathrm{SU}}\right)$, from the Climatic Digital Atlas of Catalonia (Ninyerola et al., 2000; $180 \mathrm{~m} \times 180 \mathrm{~m})]$, and distances to environmental features [water courses $\left(D_{\text {RIV }}\right)$, derived from vectorial coverages of Environmental and Housing Department of the Government of Catalonia (GENCAT, 2008)].

These environmental datasets were selected according to current knowledge of the species: the influence of temperature and humidity in determining its distribution, and also on annual cycles of species activity (Way et al., 1997; Holway et al., 2002; Krushelnycky et al., 2005; Heller et al., 2006; Abril et al., 2007; Menke et al., 2007). Mean winter minimum temperatures $\left(T_{\mathrm{WI}}\right)$ were obtained by calculating the mean of December, January, February and March minimum temperatures, and mean summer maximum temperatures $\left(T_{\mathrm{SU}}\right)$ by calculating the mean of May, June, July, August, September and October maximum temperatures. Months were selected according to the Argentine ant activity range; the period from May to October is when the species is more active at the NE Iberian Peninsula (Abril et al., 2007). The TPI is a scaledependent index that classifies the landscape into landform categories, from valleys to flat areas and mountain ranges (Tagil \& Jenness, 2008), which indirectly influence Argentine ant presence (Holway, 

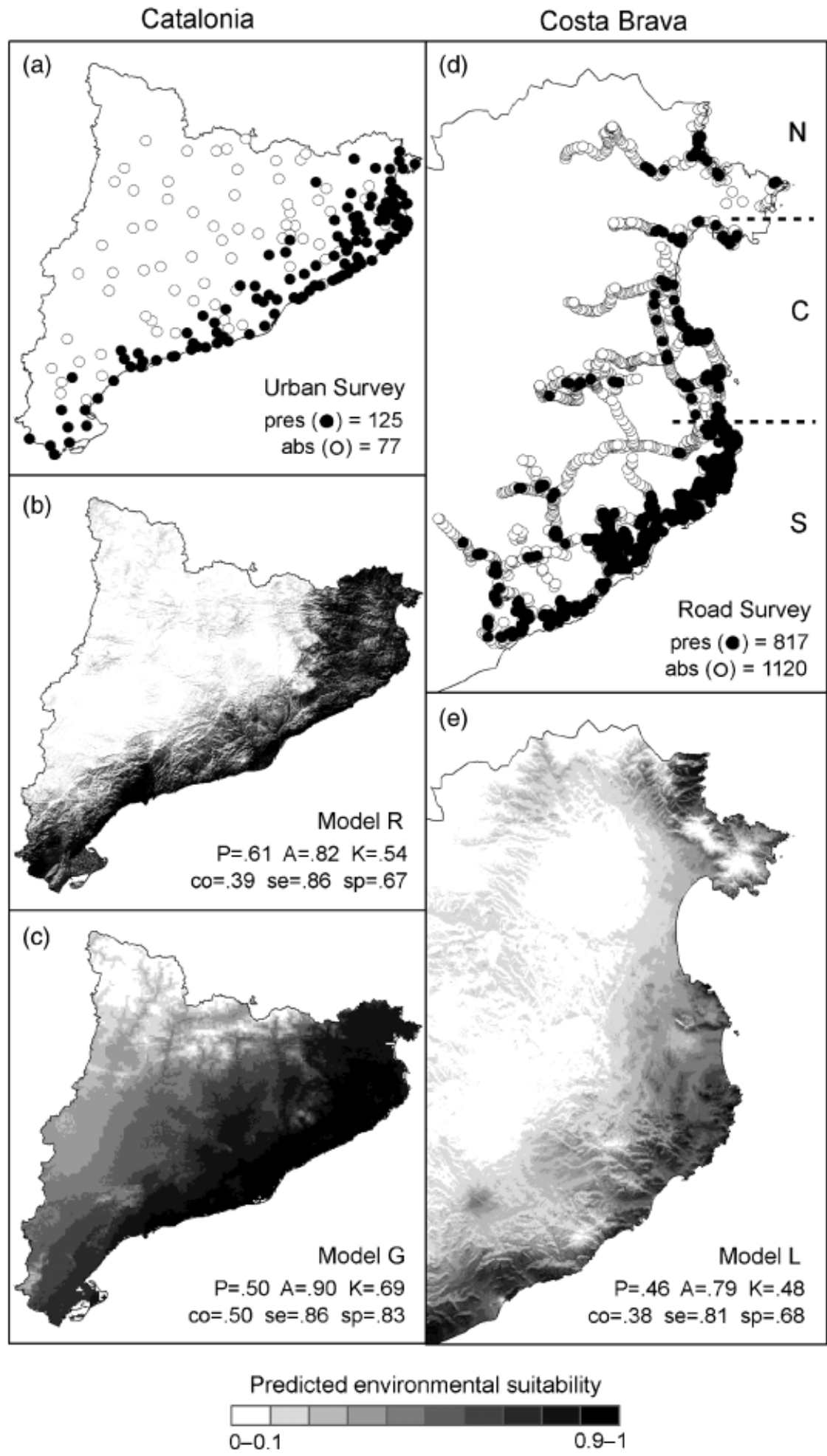

Fig. 2 Predicted potential distribution for the Argentine ant in Catalonia and Costa Brava using occurrence data at different spatial scales to calibrate ecological niche models: global (G), regional (R) and local (L). Occurrence data from the urban (a) and road (d) surveys were used to develop models (b) and (e), respectively. Model (c) was developed using worldwide occurrence data extracted from RouraPascual et al. (2004). For each model, the prevalence $(\mathrm{P})$ of the testing occurrence data and several measures of model performance are presented: AUC (A), $\kappa$ index (K), optimal cutoff (co), sensitivity (se) and specificity (sp). 
1998). The TPI was calculated based on the difference in elevation between a cell and the average elevation of the neighbouring cells at $1000 \mathrm{~m}$ distance, while accounting for the slope of that cell, using a GIS extension (Jenness, 2005). Because biotic interactions do not seems to limit Argentine ants in introduced ranges (Carpintero \& Reyes-Lopez, 2008), predictions from ecological niche models provided a good spatial representation of the species' ecological profile across spatial scales. Data for the global model were prepared at $1 \mathrm{~km}$ resolution in ARCGIS v9.2 (C)ESRI, Redlands, CA, USA), and at 180 and $30 \mathrm{~m}$ spatial resolution for the regional and local models, respectively. Climatic data were resampled at $30 \mathrm{~m}$ spatial resolution for the local model, but topographic and distance-related variables were directly generated at 180 and $30 \mathrm{~m}$. Correlated environmental variables $(r>0.7$, such as mean annual temperature) were excluded from the initial datasets.

\section{Dynamic modelling approach to simulate the jump- dispersal process at local scales}

To determine the role of human factors in shaping the distribution of the Argentine ant and to understand the spatiotemporal dynamics of the invasion, we aimed at reconstructing the history of the invasion at local scales (Costa Brava) using a spread model (Hanski, 1999). The species is known to spread mainly through jump-dispersal events associated with humans, which vary from a few to thousands of kilometres (Suarez et al., 2001). However, we limited the dispersal to short-distance jump dispersal because: (i) localities of Argentine ant tend to appear aggregated around certain nuclei, suggesting that dispersal occurs mainly among neighbouring areas; (ii) the pattern of spread in the study area is unknown and long-distance jumps are highly unpredictable; and (iii) the study area is small and highly urbanized, making human movement more frequent at short distances. Long-distance jump dispersal (across the region) was however incorporated by postulating different scenarios of arrival of the species. In doing so we combined long- and short-distance jump dispersal, and reconstructed the spatiotemporal dynamics of the Argentine ant after introductions without adopting a particular frequency distribution.

We adopted a deterministic approach and calculated the occupancy probabilities after each time step based on the initial conditions and a spread parameter. The study area $(55.8 \mathrm{~km} \times 59.22 \mathrm{~km})$ was divided into cells of size $180 \mathrm{~m} \times 180 \mathrm{~m}$, resulting in a grid of $310 \mathrm{~m} \times 529 \mathrm{~m}$ cells. Metapopulation principles were used for governing the cell-state transition called the interacting particle system model (Hanski, 1999; Lee et al., 2007). The time step $t$ was 1 year and the model was run according to the following transition rule:

$$
\begin{aligned}
P_{i, j}(t+1)= & \left(1-e_{i, j}\right) P_{i, j}(t)+\frac{c_{i, j}}{(2 z+1)^{2}-1} \\
& \left(1-P_{i, j}(t)\right)\left(\left(\sum_{x=i-z}^{i+z} \sum_{y=j-z}^{j+z} P_{x, y}(t)\right)-P_{i, j}(t)\right),
\end{aligned}
$$

where $P_{i, j}(t)$ is the probability that cell $(i, j)$ is occupied, $c_{i, j}$ and $e_{i, j}$ indicate the colonization rate and the extinction rate, and $z$ indicates the colonization distance per time step (Hui \& Li, 2004). We chose $c_{i, j}=1-\exp \left(-5 \cdot Q_{i, j}\right)$ and $e_{i, j}=\exp \left(-5 Q_{i, j}\right)$, where $Q_{i, j}$ is the quality of cell $(i, j) . Q_{i, j}$ was defined as the suitability predicted by the ecological niche model if the cell corresponded to an urban area, or zero for nonurban areas. Nonurban areas were set to zero as jump dispersal takes primarily place among urban areas. The colonization range used in the simulation was $z=5$ (five cells), representing a maximum dispersal distance of $0.9 \mathrm{~km} \mathrm{(5}$ cells $\times 180 \mathrm{~m}$ ) per time step and a square area of $1.98 \mathrm{~km} \times 1.98 \mathrm{~km}$ (11 cells $\times 11$ cells $)$ that could be potentially covered with ants coming from one occupied cell in the centre. Suarez et al. (2001) reported a jump dispersal of $>10 \mathrm{~km} \mathrm{yr}^{-1}$ in North America, while in New Zealand a distance of $2-3 \mathrm{~km} \mathrm{yr}^{-1}$ was described (Pitt et al., 2009). Considering the level of urbanization and human mobility in the Costa Brava, an annual dispersal distance of $\sim 1 \mathrm{~km}$ is reasonable and provides a sound baseline for the model. The selection of this dispersal distance did not affect the spatial dimension of the simulated range expansion, but only the temporal one (i.e. the speed of spread by slowing or accelerating the advance of the invasion).

To test several hypotheses about the introduction pathways of Argentine ants in the Costa Brava, the model was run under different scenarios of introduction and four environmental suitability mosaics [three derived from ecological niche models developed earlier at global (G), regional (R) and local (L) spatial scales; the other fixing the urban cells with a suitability of one to overcome the effect of habitat heterogeneity (U)]. The scenarios of introduction were:

- Maritime commerce in principle ports $\left(\mathrm{M}_{\mathrm{P}}\right)$ : Argentine ants arrived at two main ports in trans-Atlantic shipping routes (St Feliu de Guíxols and Palamós, Fig. 1).

- Maritime commerce in principal and main secondary ports $\left(\mathrm{M}_{\mathrm{PS}}\right)$ : In addition to the main ports (scenario $\mathrm{M}_{\mathrm{P}}$ ), the species was also introduced in some of the most relevant secondary ports during the 19th and beginning of 20th century (Blanes, Roses and Cadaqués). 
- Maritime commerce in all ports $\left(\mathrm{M}_{\mathrm{all}}\right)$ : The Argentine ant arrived to all previous ports (scenario $\mathrm{M}_{\mathrm{P}}$ and $\mathrm{M}_{\mathrm{PS}}$ ), but also in Lloret de Mar, Tossa de Mar, Calella de Palafrugell, l'Escala, and Port de la Selva by means of local maritime routes.

- Cork industry (C): The main activity promoting the spread of the invasion was the cork industry, which imported raw cork from other parts of the Iberian Peninsula where L. humile was first detected (Oporto and València). The main factories during that period were located in Cassà de la Selva, Llagostera and Palafrugell, and around the main ports (scenario $\mathrm{M}_{\mathrm{P}}$ ).

- Maritime commerce in all ports and cork industry $\left(\mathrm{M}_{\mathrm{all}} \mathrm{C}\right)$ : Argentine ant arrived simultaneously by means of maritime commerce (scenario $\mathrm{M}_{\mathrm{P}}, \mathrm{M}_{\mathrm{PS}}$ and $\mathrm{M}_{\text {all }}$ ) and cork industry (scenario $\mathrm{C}$ ).

These 20 combinations (five scenarios of arrival $\times$ four suitability mosaics) were run for 160 time steps using Mathematica Version 6.0 (CWolfram Research Inc., Champaign, IL, USA). The performance of models to predict the distribution of L. humile observed during the road survey was calculated using the AUC and $\kappa$ indices, as well as sensitivity and specificity at threshold 0.5. Contrary to the correlative modelling approach, the latter three indices were measured at a specific threshold to compare the performance of the spread model over time. Models presenting the highest performance were interpreted as the most plausible scenarios to explain the expansion of L. humile in the Costa Brava. Additionally, differences and similarities between models predictions were also tested using the $\kappa$ index as a measure of agreement.

\section{Results}

Correlative modelling approach to identify suitable areas across spatial scales

The urban survey in Catalonia corroborates the invasive pattern described by Espadaler \& Gómez (2003), which restricts Argentine ant distribution near the coast and suggests that the species is absent from inland and high altitude areas (Fig. 2a). However, the road survey indicates that the almost continuous distribution presented in the Costa Brava is further fragmented into several invasion patterns presenting different degrees of spatial continuity (Fig. 2d). Species presence increases towards the southernmost coastal areas, where the species is known to invade natural habitats (i.e. pine and cork oak forests, shrublands and dry cultivated fields). Although the Argentine ant is mainly present near urban areas in the North, it was also found invading natural environments (such as shrublands dominated by
Quercus coccifera and Cistus spp. in the Cap de Creus, Fig. 1). Similarly, in inland areas, the species showed a patchy distribution near human settlements, even though it has also been found occupying natural habitats quite a distance away from human dwellings (e.g. the invasion was found in cork oak forests at $>2 \mathrm{~km}$ from inhabited areas). These latest findings are extremely important because it shows the species ability to invade northern habitats with more extreme environmental conditions and interior natural habitats, which was not known to occur until now at NE Iberian Peninsula.

To determine the status of the invasion, we compared the prediction of the model calibrated at global scales using worldwide occurrences (in addition to the presence data obtained from the urban survey) with the regional and local models developed using occurrences from the urban and road surveys, respectively. Besides the lack of true absence data to calibrate and evaluate the model at global scales, tests indicate good model agreement in predicting data set aside from model development (AUC $=0.90 / \kappa=0.69$ ). The regional and local models developed using a more specific set of environmental data also showed high model performance $(\mathrm{AUC}=0.82 / \kappa=0.54$ and $\mathrm{AUC}=0.79 / \kappa=0.48$, respectively).

For Catalonia, the global and regional models predict a similar pattern and indicate areas along the coast as highly suitable for the Argentine ant (Fig. 2c and b). This result suggests that $L$. humile already reached its maximum geographic extent at the regional scale, and future spread will probably occur within the actual geographic limits of the invasion. For the Costa Brava, the model developed at local scales indicates that a further spread of the species is still possible near the coast, but inland areas appear less suitable (Fig. 2e). These results differ to some degree from those obtained by the global and regional models, which predict most of the Costa Brava as highly suitable. Although the model at local scales correctly predicts the occurrence data set aside as testing data, it omits some urban localities where the species is known to occur. This model adjust predictions close to areas where the Argentine ant is present at high densities (such as coastal areas) and tends to underpredict its inland distribution, probably due to the inclusion of false absences that correspond to environmentally suitable areas that have not been occupied yet.

There were some slight divergences in the influential environmental variables across spatial scales (Table 1). While the regional model only considered few variables as the most relevant ones in determining the distribution of the species, the local model included several factors at similar levels of relevance. As in the global model, this might be due to the difficulties of the model 
to reach a unique consensus prediction in highly heterogeneous environments. In other words, the occurrence set influences the calibration of the model substantially. This shows the relevance of adopting a multimodel inference method that permits the development of multiple realisations of the calibration data. Besides these divergences, both models include temperature $\left(T_{W I}\right)$ and precipitation $\left(P_{\mathrm{AN}}\right)$ as the most influential variables. This is in concordance with previous studies (Krushelnycky et al., 2005; Menke et al., 2007), which demonstrated the influence of climatic factors, especially temperate climates and humidity, on the species distribution. Thus, the inclusion of distance to rivers ( $D_{\text {RIV }}$ ) in the local model could probably be explained by the preference of Argentine ants to occupy habitats near water courses in xeric environments and the scale of the analysis (Holway et al., 2002). In general, we did not find dramatic differences in the relative importance of environmental variables when changing scales, even though ecological processes acquire new nuances when perceived from different spatial scales (Mackey \& Lindenmayer, 2001).

Dynamic modelling approach to simulate the jumpdispersal process at local scales

Spread models developed by combining scenarios of introduction and urban mosaics of environmental suitability for the Argentine ant in the Costa Brava predict a fast rate of spread in the first years, and a posterior stabilization when the most suitable areas become occupied (Fig. 3, Appendix S1). This pattern, however, varies depending on the scenario and suitability mosaic. The rate of spread under scenario $M_{P}$ (maritime commerce in principle ports) is slow during the first 100 years and then increases exponentially, whereas in the rest of scenarios the predicted area occupied increases gradually along the time period of our analysis (160 years). Scenario $\mathrm{M}_{\mathrm{all}} \mathrm{C}$ (maritime commerce in all ports and cork industry) gives the greatest range under all suitability mosaics. When comparing for the effects of suitability, mosaics U (all urban cells highly suitable), G and $\mathrm{R}$ (derived from the global and regional models, respectively) promote the greatest range expansion. By contrast, suitability L (derived from the local model) produces the smallest expansion (since there are less areas suitable for its establishment) and the maximum number of occupied cells is reached sooner than in the other suitability contexts.

To identify the most plausible scenario of introduction, we compared the performance of all models using both AUC and $\kappa$ indices. Besides their differences, both measures show similar patterns: high increase in model performance during the first 20-40 years since introduction and then a slight decrease over time (Fig. 4). This decrease is specially accentuated when models are calibrated using suitability $\mathrm{U}, \mathrm{G}$ and $\mathrm{R}$, and almost nonexistent for suitability L. In general, the model showing the highest performance over time under all suitability mosaics is scenario $\mathrm{M}_{\text {all }}$ (maritime commerce in all ports), followed by scenario $\mathrm{M}_{\mathrm{all}} \mathrm{C}$ under suitability $\mathrm{R}$ and $\mathrm{L}$ and during the first years under the other suitability mosaics. It is important to note that models developed under scenario $M_{P}$ tended to outperform models calibrated using other scenarios at the end of the temporal sequence. This is partly due to the nature of the evaluation indices, which penalize the inclusion of both false predicted presences and absences.

These patterns can also be observed by identifying the year at which models attain the highest performance (Fig. 5). Besides the limitations of the spread model for assessing the year of introduction of the invasion, the number of years required to reach the maximum model performance varied quite uniformly depending on the scenario of arrival $\left(\mathrm{M}_{\mathrm{P}}>\mathrm{M}_{\mathrm{PS}}>\right.$ $\left.\mathrm{C}>\mathrm{M}_{\text {all }}>\mathrm{M}_{\text {all }} \mathrm{C}\right)$ and the suitability mosaic $(\mathrm{L}>\mathrm{G} \sim$

Table 1 Relative importance (in \%) of predictor variables included in the ecological niche models assessing the potential distribution of the Argentine ant using occurrence data at global (G), regional (R), and local (L) scales

\begin{tabular}{|c|c|c|c|c|}
\hline \multicolumn{2}{|l|}{ Model G } & \multicolumn{2}{|l|}{ Model R } & \multirow{2}{*}{$\frac{\text { Model L }}{\text { Relative importance (\%) }}$} \\
\hline Variables & Relative importance (\%) & Variables & Relative importance (\%) & \\
\hline$P_{\mathrm{AN}}$ & 16.40 & ASP & 26.95 & 5.60 \\
\hline MDR & 16.76 & SLO & 5.59 & 4.49 \\
\hline TMIN & 16.76 & TPI & 2.84 & 15.16 \\
\hline TMAX & 16.76 & $R_{\mathrm{AN}}$ & 7.68 & 15.29 \\
\hline$P_{\mathrm{CQ}}$ & 16.76 & $P_{\mathrm{AN}}$ & 25.53 & 15.29 \\
\hline \multirow[t]{3}{*}{$P_{\mathrm{WQ}}$} & 16.58 & $T_{\mathrm{WI}}$ & 27.03 & 15.29 \\
\hline & & $T_{\mathrm{SU}}$ & 2.26 & 14.92 \\
\hline & & $D_{\mathrm{RIV}}$ & 2.10 & 13.95 \\
\hline
\end{tabular}

See 'Methods' for the description of abbreviations. 

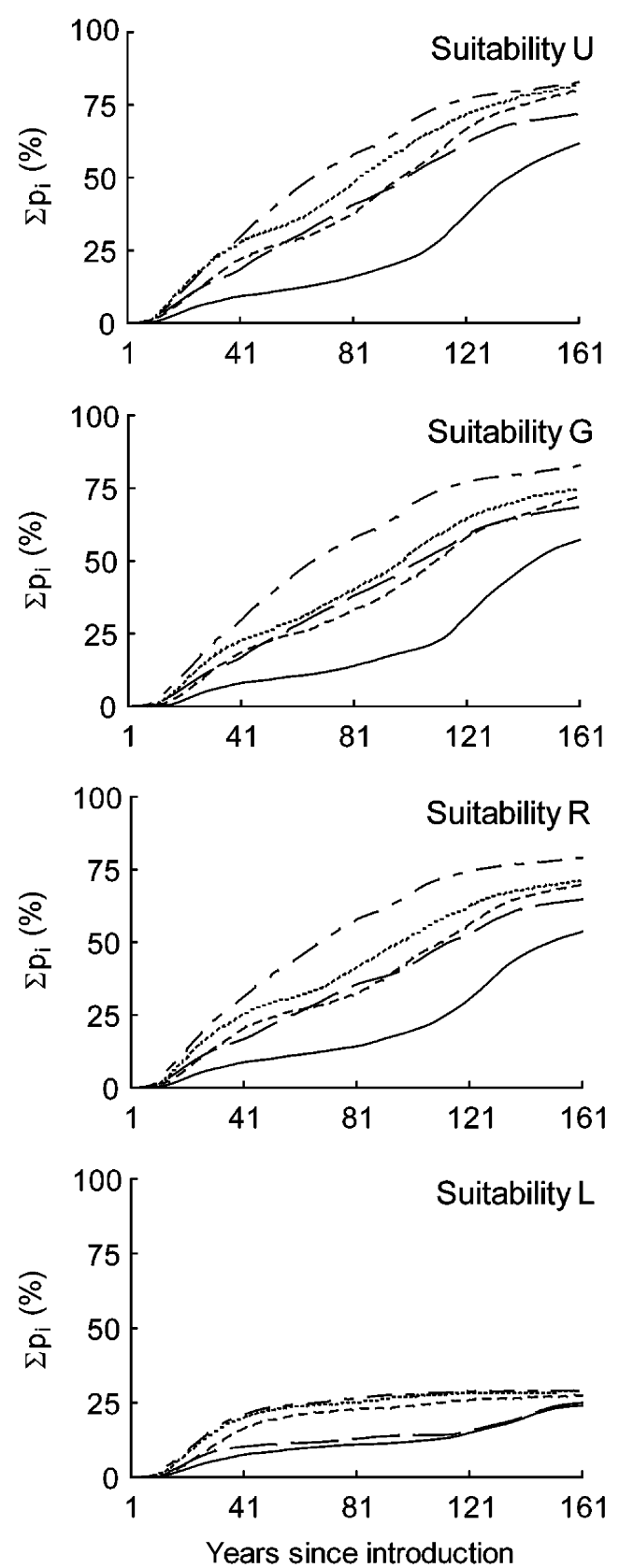

Fig. 3 Percentage of area predicted occupied by the Argentine ant in 160 years time. $y$-axis refers to the area predicted occupied, measured as the sum of all cells' probability $\left(\Sigma \mathrm{p}_{\mathrm{i}}\right)$. $x$-axis indicate the number of years since introduction. Lines refer to scenarios of introduction: $\mathrm{M}_{\mathrm{P}}(-), \mathrm{M}_{\mathrm{PS}}(---), \mathrm{M}_{\text {all }}$ $(\ldots), \mathrm{C}(---)$, and $\mathrm{M}_{\text {all }} \mathrm{C}(---)$.

$\mathrm{R} \sim \mathrm{U})$. All predictions indicate that areas near the coast are probably the most occupied at present day, and a more patchy distribution up to northernmost areas. This pattern was also observed during the road survey (Fig. 2d). Argentine ants tend to cluster near the original focuses of introduction forming a small sample of historically related populations which are not independent of the distance from the focus of introduction, as often assumed as a result of jump-dispersal processes. Comparisons among predictions (Fig. 5) across suitability mosaics indicate that scenarios $M_{P}$ and $C$ produce different spatial results than scenarios $\mathrm{M}_{\mathrm{PS}}$, $\mathrm{M}_{\text {all }}$ and $\mathrm{M}_{\text {all }} \mathrm{C}$ (Table 2a). On the other hand, when comparing for the effects of the suitability mosaic, it seems that predictions derived from suitability $\mathrm{U}, \mathrm{R}$ and $\mathrm{G}$ tend to be slightly more similar than those representations derived from suitability L (Table 2b).

Comparing the performance of the spread models under suitability L (Fig. 5, last row) with that from the ecological niche model at local scales (which reflects a scenario of unlimited dispersal, Fig. 2e), the spread model performed almost as well as the ecological niche model. The only difference is that the spread model presents a slightly lower sensitivity and a slightly higher specificity than the other. As a result, the spread model can be recommended as a refinement of the ecological niche model, keeping in mind the risk of underestimating the current distribution range of the Argentine ant in the Costa Brava. Comparisons among all model predictions (Figs 2 and 5) were not possible due to differences in prevalence among datasets (Manel et al., 2001; McPherson et al., 2006).

\section{Discussion}

Question 1: Is Argentine ant invasion in equilibrium with its environment?

The development of ecological niche models at nested spatial scales appears to be an appropriate approach to assess the range of suitable conditions for invasive species. It enables a reasonable estimate of the geographic dimensions of the invasion, and provides information about its equilibrium status. In this sense, global/regional models are expected to be more robust than local models in predicting the potential distribution of species, even when the species is not in equilibrium (Bolliger et al., 2000). Models built at global/ regional scales tend to capture a larger proportion of the species potential distribution than local models, which are calibrated using a narrower range of environmental conditions. Therefore, while areas predicted as highly suitable by the model calibrated at local scales are prone to invasion, nonsuitable areas cannot.

Comparison of models calibrated at global and regional scales showed that differences between predictions are insignificant, suggesting that L. humile might have already reached its maximum geographic extent at regional scales (Catalonia). However, comparisons between predictions at regional and local scales suggest 

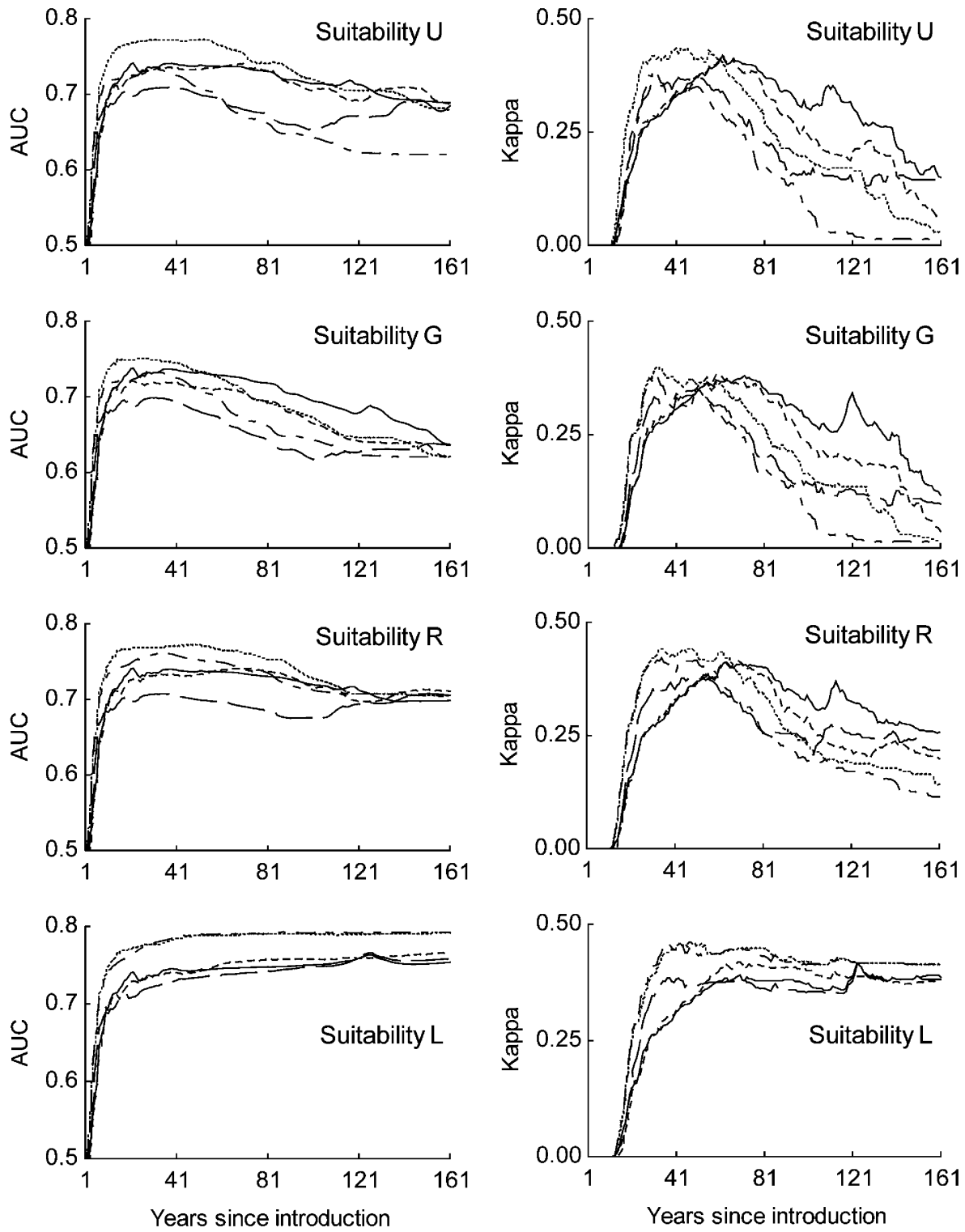

Fig. 4 Models performance measured using AUC and $\kappa$ indices. $y$-axis refer to the value of the indice, and $x$-axis the number of years since introduction. Lines refer to scenarios of introduction: $\mathrm{M}_{\mathrm{P}}(-), \mathrm{M}_{\mathrm{PS}}(---), \mathrm{M}_{\text {all }}(\ldots), \mathrm{C}(---)$, and $\mathrm{M}_{\text {all }} \mathrm{C}(---)$.

that the invasion is not in equilibrium at local scales (Costa Brava), and indicate that the species still has potential to occupy optimal urban areas within the limits predicted at global/regional scales and spread into natural habitats in our study system. In fact,
Casellas (2004) reported an increasing net expansion rate of the invasion by budding (similar to diffusion dispersal) of $19.00 \pm 6.83 \mathrm{~m} \mathrm{yr}^{-1}(n=1)$ in a forested area of the southern Costa Brava. Even though this rate of spread is somewhat smaller than the rates reported in

Fig. 5 Model predictions of Argentine ant spread in the Costa Brava under five scenarios of introduction (scenario $M_{P}, M_{P S}, M_{a l l}, C$, $\mathrm{M}_{\mathrm{all}} \mathrm{C}$ ) and four suitability mosaics [all urban areas equally suitable (U), and suitability based on global (G), regional (R), and local (L) predictions] for the year attaining the maximum model performance based on the $\kappa$ index (threshold 0.5). Maximum AUC (A) and $\kappa$ (K) indices, as well as the year in which they are attained between parentheses, are presented. Sensitivity (se) and specificity (sp) at threshold 0.5 are also included. ${ }^{*}$ Instead of using year 151 (when AUC index was highest), we provide the AUC corresponding to the first peak at 32 years. 
Scenario $M_{P} \quad$ Scenario $M_{P S} \quad$ Scenario $M_{\text {all }} \quad$ Scenario $C \quad$ Scenario $M_{\text {all }} C$

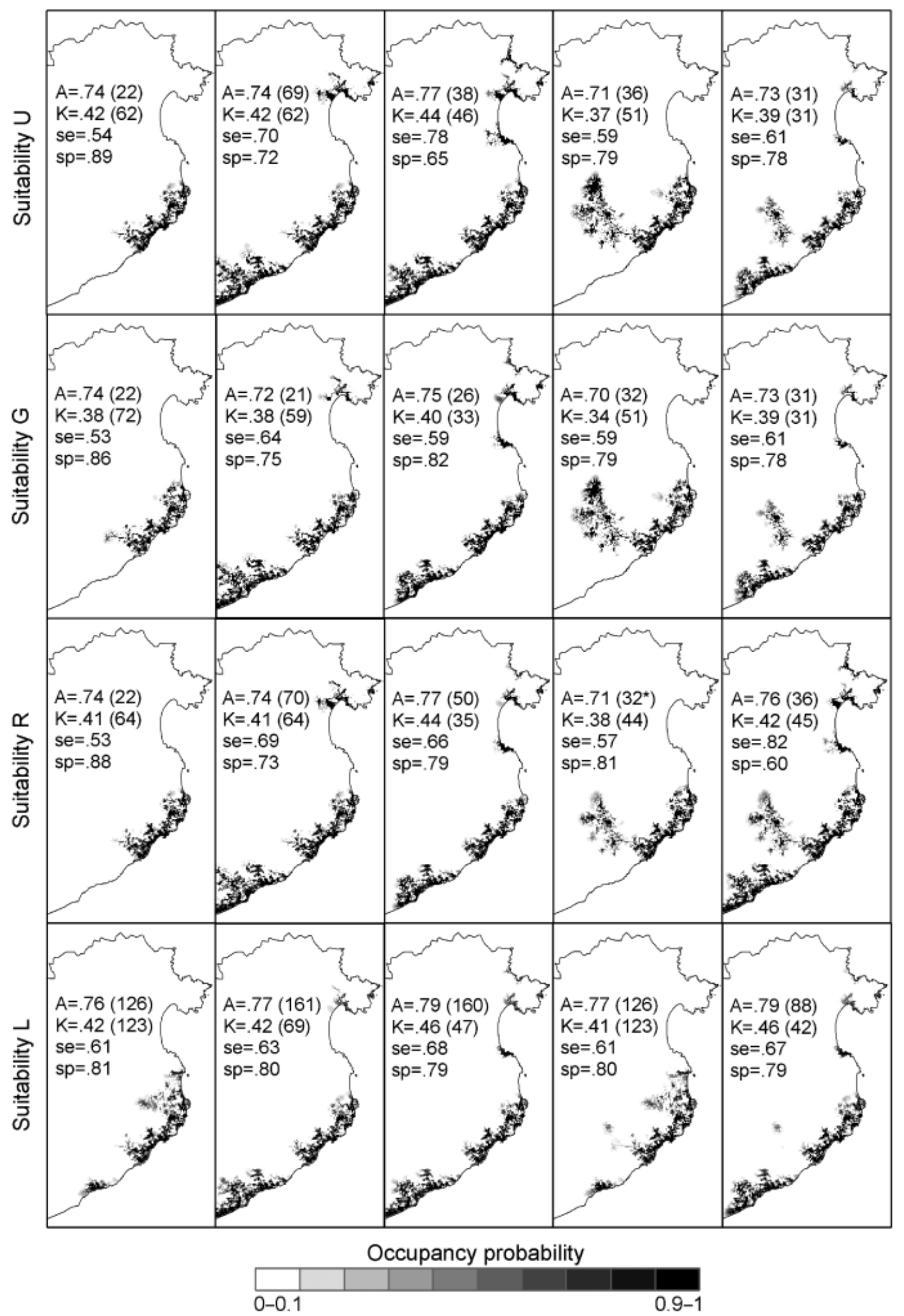


other parts of the world (Suarez et al., 2001), it shows the potential of the species to invade new areas in the region without human assistance. Therefore, it is necessary to monitor the invasion in other urbanized areas and natural habitats of the Costa Brava, and identify the environmental constraints that might limit its expansion at local scales.

Question 2: What are the main pathways of introduction and expansion of the Argentine ant?

Besides the complex processes governing the dispersal of species, considerable progress has been made in the development of spread models of invasions (Hastings et al., 2005). Similar to Pitt et al.(accepted) that simulated local diffusion and long-distance events as differentiated processes, we considered human-mediated shortand long-distance jump dispersal as the primary mechanisms governing the spread of the Argentine ant in the Costa Brava. The range expansion through local diffusion was not considered because the expected yearly rate of spread by budding $\left(<150 \mathrm{~m} \mathrm{yr}^{-1}\right.$ on average; Suarez et al., 2001) would not be sufficient for the Argentine ant to reach its current distribution if initially introduced in only one or two localities. Our model, however, did not consider the frequency distribution of jump-dispersal distances (Suarez et al., 2001), but focused only on the extreme limits of the dispersal spectrum. Long-distance jump dispersal was incorporated into the design through the scenarios of introduction, and short-distance jump dispersal simulated using the spread model. By limiting the dispersal of the species we avoided the calculating complexity with a certain risk of underestimating the capacity of the species to disperse among distant areas. This is reflected in the lower sensitivity values of the spread models in comparison to the ecological niche model, which can be interpreted as a scenario of unlimited dispersal. However, based on our current knowledge of the invasion and the lack of data on the dynamics of the invasion, our spread model constitutes a reasonable trade-off between the development of a realistic, practical model and the inclusion of unavailable records or unverified assumptions. Overall, the spread model enabled the reconstruction of the spatiotemporal dynamics of the invasion, and identified the influence of various environmental suitability mosaics and humanmediated scenarios of arrival.

The hypothetical arrival of the Argentine ant through maritime commerce and subsequent jump dispersal associated with humans (Suarez et al., 2001) appears to be the most plausible hypothesis explaining the introduction of the species in the NE Iberian Peninsula. The first propagules most likely arrived at the south- ernmost coastal areas of the Costa Brava. Boats from South America (especially from Rio de la Plata) stopped at the main southern harbours (scenario $\mathrm{M}_{\mathrm{P}}$ ), and from there cargo were delivered by boat or wheeled transport to the rest of the coast (scenario $\mathrm{M}_{\text {all }}$ ) (Barbaza, 1988). Before their arrival, these boats followed strategic transAtlantic routes that surprisingly linked the main invaded areas of eastern America with the NE Iberian Peninsula: Rio de la Plata, Montevideo/Buenos Aires, Cuba and New Orleans (Fradera \& Yáñez, 1995). Although the importation of raw cork from SW Iberian Peninsula does not seem to play an important role, the performance of models calibrated under scenarios $\mathrm{M}_{\mathrm{all}} \mathrm{C}$ and $\mathrm{C}$ is quite relevant and its importance in inland areas cannot be dismissed. In fact, most of the inland localities occupied by Argentine ants were close to cork deposits (N. Roura-Pascual, personal observation) and this finding suggests that cork industries may have facilitated secondary jump dispersal.

While we cannot identify the exact date of introduction and the type of cargo involved in the expansion of the Argentine ant, our results suggest that the species must have been successfully introduced into different areas along the Costa Brava. This supports our hypothesis that L. humile arrived by means of several jumpdispersal events at multiple sites. However, the almost continuous distribution of the species in the southernmost coastal areas seems to indicate that the Argentine ant arrived earlier. The importance of southern harbours (those included in scenario $\mathrm{M}_{\mathrm{P}}$ ) for trans-Atlantic routes during 19th century and cork industries during 20th century, and the fast expansion of the urban development in the last decades (Barbaza, 1988; Martí Llambrich, 2005), are the most probable reasons explaining the high occupancy of the Argentine ant in this southernmost coastal area. It is also noteworthy that the first reported records of Argentine ants in the Costa Brava (to our knowledge) date back to 1940s in S'Agaró (near Sant Feliu de Guíxols, Catalonia; Fig. 1) (Goetsch, 1942).

Relating this hypothesis on the arrival of the Argentine ant with the actual knowledge on the population biology of the species, raises interesting and challenging unresolved questions about the origin of the introduced populations. Compared with North America (Tsutsui et al., 2001), there are only two supercolonies present in the Mediterranean basin; while most of the region seems occupied by the same (so-called the European) supercolony, Giraud et al. (2002) also identified another supercolony at the NE Iberian Peninsula (so-called Catalan). Both colonies appear intermingled in the Costa Brava (S. Abril, personal observation), indicating that at least two different sources of introduction could have been in the area. These two sources could be the trans-Atlantic routes and cork industries as highlighted 
Table 2 Comparisons between predictions derived from the dynamic spread models (presented in Fig. 5) using the $\kappa$ index. Results are presented grouped by: (a) suitability mosaic [all urban areas equally suitable (U), and suitability based on global (G), regional (R), and local (L) predictions], and (b) scenario of introduction $\left(M_{P}, M_{P S}, M_{a l l}, C, M_{\text {all }} C\right)$. See Methods for the description of abbreviations

(a) $K$ by suitability mosaic

\begin{tabular}{|c|c|c|c|c|}
\hline & $\mathrm{M}_{\mathrm{P}}$ & $\mathrm{M}_{\mathrm{PS}}$ & $\mathrm{M}_{\text {all }}$ & C \\
\hline \multicolumn{5}{|c|}{ Suitability U } \\
\hline $\mathrm{M}_{\mathrm{PS}}$ & 0.51 & & & \\
\hline $\mathrm{M}_{\text {all }}$ & 0.46 & 0.88 & & \\
\hline $\mathrm{C}$ & 0.59 & 0.25 & 0.22 & \\
\hline $\mathrm{M}_{\mathrm{all}} \mathrm{C}$ & 0.46 & 0.61 & 0.61 & 0.41 \\
\hline \multicolumn{5}{|c|}{ Suitability G } \\
\hline $\mathrm{M}_{\mathrm{PS}}$ & 0.48 & & & \\
\hline $\mathrm{M}_{\text {all }}$ & 0.49 & 0.79 & & \\
\hline $\mathrm{C}$ & 0.61 & 0.25 & 0.27 & \\
\hline $\mathrm{M}_{\mathrm{all}} \mathrm{C}$ & 0.49 & 0.69 & 0.84 & 0.44 \\
\hline \multicolumn{5}{|c|}{ Suitability $R$} \\
\hline $\mathrm{M}_{\mathrm{PS}}$ & 0.51 & & & \\
\hline $\mathrm{M}_{\text {all }}$ & 0.52 & 0.77 & & \\
\hline $\mathrm{C}$ & 0.74 & 0.36 & 0.38 & \\
\hline $\mathrm{M}_{\mathrm{all}} \mathrm{C}$ & 0.39 & 0.73 & 0.69 & 0.58 \\
\hline \multicolumn{5}{|c|}{ Suitability L } \\
\hline $\mathrm{M}_{\mathrm{PS}}$ & 0.54 & & & \\
\hline $\mathrm{M}_{\text {all }}$ & 0.51 & 0.93 & & \\
\hline $\mathrm{C}$ & 0.99 & 0.53 & 0.51 & \\
\hline $\mathrm{M}_{\mathrm{all}} \mathrm{C}$ & 0.54 & 0.91 & 0.96 & 0.54 \\
\hline
\end{tabular}

(b) $K$ by scenario of introduction

\begin{tabular}{llll}
\hline & $\mathrm{U}$ & $\mathrm{G}$ & $\mathrm{R}$ \\
Scenario $M_{P}$ & & & \\
$\mathrm{G}$ & 0.89 & 0.89 & \\
$\mathrm{R}$ & 0.99 & 0.72 & 0.74 \\
$\mathrm{~L}$ & 0.73 & & \\
Scenario $M_{P S}$ & & & \\
$\mathrm{G}$ & 0.90 & 0.91 & 0.87 \\
$\mathrm{R}$ & 0.98 & 0.87 & \\
$\mathrm{~L}$ & 0.86 & & \\
Scenario $M_{\text {all }}$ & & & \\
$\mathrm{G}$ & 0.71 & 0.89 & \\
$\mathrm{R}$ & 0.80 & 0.82 & \\
$\mathrm{~L}$ & 0.84 & & \\
Scenario C & & & \\
$\mathrm{G}$ & 0.96 & 0.78 & \\
$\mathrm{R}$ & 0.81 & 0.45 & \\
$\mathrm{~L}$ & 0.49 & & \\
Scenario $M_{\text {all }} \mathrm{C}$ & & & \\
$\mathrm{G}$ & 1.00 & 0.68 & \\
$\mathrm{R}$ & 0.68 & 0.75 & \\
$\mathrm{~L}$ & 0.75 & &
\end{tabular}

by our results. However, other circumstances could also be responsible for such distributional patterns. Although southern harbours (scenario $\mathrm{M}_{\mathrm{P}}$ ) had direct contacts with the native range of the species, they also received products from South America indirectly via Barcelona. More comparisons on the genetics of L. humile in its native and introduced ranges are needed to test this hypothesis and broaden our understanding of its population structure in introduced ranges (Corin et al., 2007).

\section{Conclusions}

In summary, our results suggest that the Argentine ant might have reached its maximum distribution in Catalonia at the regional scale, but a further expansion of the species at local scales is highly probable. This is especially true for urban areas in the Costa Brava, which provide suitable environmental conditions for the establishment of the species. The current distribution of L. humile seems to be mainly restricted to the major focus of introduction, coastal areas. Our simulations suggest that the species would have been introduced successfully at multiple coastal localities (scenario $\mathrm{M}_{\mathrm{all}}$ ), although some inland localities (scenario $\mathrm{M}_{\mathrm{all}} \mathrm{C}$ ) could have also been occupied at an early stage of the invasion. Therefore, further expansions of the species into coastal and inland urban areas could be expected in the future.

From a methodological perspective, the use of occurrence data at different spatial scales and the combination of these two modelling approaches provide new insights into the understanding of the Argentine ant invasion. The most remarkable contribution of adopting a multiscalar modelling approach is that it allowed us to evaluate the equilibrium status of the invasion, and estimate the geographic dimensions of the Argentine ant invasion. As found in other studies (Thomas \& Abery, 1995; Hartley \& Kunin, 2003), it seems that coarse scale predictions are poorer indicators of changes in the expansion of species than fine scale ones. Additionally, the combination of both ecological niche and spread models allowed us to infer hypotheses about the introduction of the species in the Costa Brava and also to determine future patterns of spread. Several studies have assessed its geographic limits by means of ecological niche and spread models (Roura-Pascual et al., 2004; Krushelnycky et al., 2005; Hartley et al., 2006; Roura-Pascual et al., 2006; Menke et al., 2009), but none of these studies combined both approaches to disentangle the invasion of the species across spatial scales and reconstruct the pathways of introduction. In the future, similar sampling and modelling practices on natural habitats at different spatial scales will be necessary to determine the exact geographic dimensions of the Argentine ant invasion outside urban areas. 
Likewise, genetic analysis among historically related populations are recommended in order to retrace the history of the Argentine ant invasion in more detail and provide new insights into the capacity of different genotypes to establish viable populations. This information enables the identification of the factors responsible for its present distribution, and formulates guidelines to prevent/mitigate the expansion of the Argentine ant invasion in highly sensitive areas. The spatial dimensions of the Argentine ant invasion are enormous and somewhat out of control, but the establishment of different colonies with different genotypes and unicolonial behaviours could potentially reduce the expansion of the invasion and mitigate its ecological impacts in some specific areas.

\section{Acknowledgements}

Special thanks to A. Seglar and M. Rot for their significant assistance during the field work. C. Gómez, P. Pons, X. Espadaler, J. S. Pedersen, M. Luoto, J. J. le Roux and two anonymous referees provided valuable comments on earlier drafts of this manuscript, and C. Yáñez interesting remarks on historical data. SIGTE provided GIS support with the environmental data preparation. Financial support for this study came from Beatriu de Pinós postdoctoral grant (2006 BP-A 10124) from Catalan Agency for Management of University and Research Grants (in support of NRP), the Ministry of Education and Science of the Spanish Government CGL2004-05240-C02-02/BOS (NRP and JMB).

\section{References}

Abril S, Oliveras J, Gomez C (2007) Foraging activity and dietary spectrum of the Argentine ant (Hymenoptera: Formicidae) in invaded natural areas of the northeast Iberian Peninsula. Environmental Entomology, 36, 1166-1173.

Akaike H (1974) A new look at the statistical model identification. IEEE Transactions on Automatic Control, 19, 716-723.

Barbaza Y (1988) El Paisatge humà de la Costa Brava. Edicions 62, Barcelona.

Bolliger J, Kienast F, Bugmann H (2000) Comparing models for tree distributions: concept, structures, and behavior. Ecological Modelling, 134, 89-102.

Burnham KP, Anderson DR (2002) Model Selection and Multimodal Inference: A Practical Information-Theoretic Approach. SpringerVerlag, New York.

Carpintero S, Reyes-Lopez J (2008) The role of competitive dominance in the invasive ability of the Argentine ant (Linepithema humile). Biological Invasions, 10, 25-35.

Casellas D (2004) Tasa de expansión de la hormiga argentina, Linepithema humile (Mayr 1868), (Hymenoptera, Dolichoderine) en un área mediterránea. Boletín de la Asociación Española de Entomología, 28, 207-216.

Corin SE, Abbott KL, Ritchie PA, Lester PJ (2007) Large scale unicoloniality: the population and colony structure of the invasive Argentine ant (Linepithema humile) in New Zealand. Insectes Sociaux, 54, 275-282.
Espadaler X, Gómez C (2003) The Argentine ant, Linepithema humile, in the Iberian Peninsula. Sociobiology, 42, 187-192.

Fradera JM, Yáñez C (1995) Catalunya i ultramar: poder i negoci a les colònies espanyoles (1750-1914). Consorci de les Drassanes de Barcelona: Ambit Serveis Editorials, Barcelona, 221pp.

Freeman E (2007) PresenceAbsence: An R Package for PresenceAbsence Model Evaluation. USDA Forest Service, Ogden.

GENCAT (2008) Web of the Environmental and Housing Department of the Government of Catalonia. Generalitat de Catalunya, Barcelona. Available at: http://mediambient.gencat.net (accessed 26 June 2005).

Giraud T, Pedersen JS, Keller L (2002) Evolution of supercolonies: the Argentine ants of southern Europe. Proceedings of the National Academy of Sciences of the United States of America, 99, 6075-6079.

Goetsch W (1942) Beiträge zur biologie spanischer ameisen. EOS, 18, 175-241.

Guisan A, Graham CH, Elith J, Huettmann F (2007) Sensitivity of predictive species distribution models to change in grain size. Diversity and Distributions, 13, 332-340.

Guisan A, Thuiller W (2005) Predicting species distribution: offering more than simple habitat models. Ecology Letters, 8 , 993-1009.

Hanley JA, McNeil BJ (1982) The meaning and use of the area under a receiver operating characteristic (ROC) curve. Radiology, 143, 29-36.

Hanski I (1999) Metapopulation Ecology. Oxford University Press, Oxford.

Hartley S, Harris R, Lester PJ (2006) Quantifying uncertainty in the potential distribution of an invasive species: climate and the Argentine ant. Ecology Letters, 9, 1068-1079.

Hartley S, Kunin WE (2003) Scale dependency of rarity, extinction risk, and conservation priority. Conservation Biology, 17, 1559-1570.

Hastie TJ, Tibshirani RJ (1990) Generalized Additive Models. Chapman and Hall, London.

Hastings A, Cuddington K, Davies KF et al. (2005) The spatial spread of invasions: new developments in theory and evidence. Ecology Letters, 8, 91-101.

Heller NE, Sanders NJ, Gordon DM (2006) Linking temporal and spatial scales in the study of an Argentine ant invasion. Biological Invasions, 8, 501-507.

Higgins SI, Richardson DM (1996) A review of models of alien plant spread. Ecological Modelling, 87, 249-265.

Higgins SI, Richardson DM, Cowling RM (1996) Modeling invasive plant spread: the role of plant-environment interactions and model structure. Ecology, 77, 2043-2054.

Hijmans RJ, Cameron SE, Parra JL, Jones PG, Jarvis A (2005) Very high resolution interpolated climate surfaces for global land areas. International Journal of Climatology, 25, 1965-1978.

Holway DA (1998) Factors governing rate of invasion: a natural experiment using Argentine ants. Oecologia, 115, 206-212.

Holway DA, Suarez AV, Case TJ (2002) Role of abiotic factors in governing susceptibility to invasion: a test with Argentine ants. Ecology, 83, 1610-1619.

Hui C, Li ZZ (2004) Distribution patterns of metapopulation determined by allee effects. Population Ecology, 46, 55-63. 
Hulme PE (2003) Biological invasions: winning the science battles but losing the conservation war? Oryx, 37, 178-193.

ICC (2008) Web of the Institut Cartogràic de Catalunya. Institut Cartogràfic de Catalunya, Barcelona. Available at: http:// www.icc.cat (accessed 27 February 2003).

Jenness J (2005) Topographic Position Index (tpi_jen.avx) Extension for ArcView 3.x. ArcView 3.2 script, Jenness Enterprises, Flagstaff.

Krushelnycky PD, Joe SM, Medeiros AC, Daehler CC, Loope LL (2005) The role of abiotic conditions in shaping the long-term patterns of a high-elevation Argentine ant invasion. Diversity and Distributions, 11, 319-331.

Lee SD, Park S, Park YS, Chung YJ, Lee BY, Chon TS (2007) Range expansion of forest pest populations by using the lattice model. Ecological Modelling, 203, 157-166.

Lobo JM, Jimenez-Valverde A, Real R (2008) AUC: a misleading measure of the performance of predictive distribution models. Global Ecology and Biogeography, 17, 145-151.

Lowe S, Browne M, Boudjelas S, De Poorter M (2000) 100 of the World's Worst Invasive Alien Species A Selection from the Global Invasive Species Database. IUCN, New Zealand. Available at: http://www.issg.org/database (accessed 1 April 2008).

Mack MC, Simberloff D, Lonsdale WM, Evens H, Ceout M, Bazzaz FA (2000) Biotic invasions: causes, epidemiology, global consequences, and control. Ecological Applications, 10, 689710.

Mackey BG, Lindenmayer DB (2001) Towards a hierarchical framework for modelling the spatial distribution of animals. Journal of Biogeography, 28, 1147-1166.

Manel S, Williams HC, Ormerod SJ (2001) Evaluating presenceabsence models in ecology: the need to account for prevalence. Journal of Applied Ecology, 38, 921-931.

Martí Llambrich C (2005) La transformació del paisatge litoral de la Costa Brava: Anàlisi de l'evolució (1956-2003), diagnosi de l'estat actual i prognosi de futur. Unpublished PhD thesis, Universitat de Girona, Girona, xvi +463 pp.

McPherson JM, Jetz W, Rogers DJ (2006) Using coarse-grained occurrence data to predict species distributions at finer spatial resolutions-possibilities and limitations. Ecological Modelling, 192, 499-522.

Meentemeyer RK, Anacker BL, Mark W, Rizzo DM (2008) Early detection of emerging forest disease using dispersal estimation and ecological niche modeling. Ecological Applications, 18, 377390.

Menke SB, Fisher RN, Jetz W, Holway DA (2007) Biotic and abiotic controls of Argentine ant invasion success at local and landscape scales. Ecology, 88, 3164-3173.

Menke SB, Holway DA, Fisher RN, Jetz N (2009) Characterizing and predicting species distributions across environments and scales: Argentine ant occurrences in the eye of the beholder. Global Ecology and Biogeography, 18, 50-63.

Ninyerola M, Pons X, Roure JM (2000) A methodological approach of climatological modelling of air temperature and precipitation through GIS techniques. International Journal of Climatology, 20, 1823-1841.
Peterson AT (2003) Predicting the geography of species' invasions via ecological niche modeling. Quarterly Review of Biol$o g y, 78,21-35$.

Pitt JP, Worner SP, Suarez AV (2009) Predicting Argentine ant spread over the heterogeneous landscape using a spatiallyexplicit stochastic model. Ecological Applications, in press.

Roura-Pascual N, Suarez AV, Gómez C, Pons P, Touyama Y, Wild AL, Peterson AT (2004) Geographical potential of Argentine ants (Linepithema humile Mayr) in the face of global climate change. Proceedings of the Royal Society of London Series BBiological Sciences, 271, 2527-2535.

Roura-Pascual N, Suarez AV, McNyset K et al. (2006) Niche differentiation and fine-scale projections for Argentine ants based on remotely sensed data. Ecological Applications, 16, 1832-1841.

Suarez AV, Holway DA, Case TJ (2001) Patterns of spread in biological invasions dominated by long-distance jump dispersal: insights from Argentine ants. Proceedings of the National Academy of Sciences of the United States of America, 98, 1095-1100.

Tagil S, Jenness J (2008) GIS-based automated landform classification and topographic, landcover and geologic attributes of landforms around the Yazoren Polje, Turkey. Journal of Applied Sciences, 8, 910-921.

Thomas CD, Abery JCG (1995) Estimating rates of butterfly decline from distribution maps - the effect of scale. Biological Conservation, 73, 59-65.

Thuiller W, Slingsby JA, Privett SDJ, Cowling RM (2007) Stochastic species turnover and stable coexistence in a fire-prone plant community. PloS One, 2, e938, doi: 10.1371/journal. pone.0000938.

Tsutsui ND, Suarez AV, Holway DA, Case TJ (2001) Relationships among native and introduced populations of the Argentine ant (Linepithema humile) and the source of introduced populations. Molecular Ecology, 10, 2151-2161.

Way MJ, Cammell ME, Paiva MR, Collingwood CA (1997) Distribution and dynamics of the Argentine ant Linepithema (Iridomyrmex) humile (Mayr) in relation to vegetation, soil conditions, topography and native competitor ants in Portugal. Insectes Sociaux, 44, 415-433.

Yáñez C (1996) Saltar con red. La temprana emigración catalana a América ca. 1830-1870. Alianza Editorial SA, Madrid.

Youden WJ (1950) Index for rating diagnostic tests. Cancer, 3, 32-35.

\section{Supporting Information}

Additional Supporting Information may be found in the online version of this article:

Appendix S1. Model predictions of Argentine ant distribution in the Costa Brava under five scenarios of introduction: MP (a), MPS (b), Mall (c), C (d), and MallC (e), and four suitability mosaics (all urban areas are suitable (U), and suitability based on global (G), regional (R), and local (L) model predictions) at four different years since introduction.

Please note: Wiley-Blackwell are not responsible for the content or functionality of any supporting materials supplied by the authors. Any queries (other than missing material) should be directed to the corresponding author for the article. 